\title{
TALENTO MUSICAL: REVISÃO SISTEMÁTICA DE PRODUÇÕES EM BANCO DE DADOS
}

\section{Music talent: a systematic review of database production}

\author{
Fabiana Oliveira Koga - Universidade Estadual Paulista/Brasil \\ Rosemeire de Araújo Rangni - Universidade Federal de São Carlos/Brasil
}

\begin{abstract}
RESUMO: A manifestação do talento musical pode ocorrer em qualquer pessoa, em diferentes momentos da vida e em todas as esferas sociais e econômicas. A identificação e avaliação do talento musical são tarefas consideradas complexas e a resposta educativa para o indivíduo talentoso requer investimento, seja ele governamental e/ou de iniciativas independentes do poder público. A partir desse entendimento, questionou-se quais são as produções científicas, em âmbito nacional e internacional, relacionadas à identificação e avaliação do talento musical na perspectiva educacional. Sendo assim, o objetivo dessa pesquisa foi buscar e analisar as produções científicas, em âmbio nacional e internacional, relacionadas à idenficação e avaliação do talento musical na perspectiva educacional. Para alcançar esse objetivo, realizou-se revisão sistemática em três bancos de dados, dois nacionais e um internacional, sem recorte temporal. A análise dos dados realizada se deu de forma qualitativa. Como resultado, foram encontradas quatro pesquisas empíricas dedicadas à identificação e avaliação do talento musical mediante instrumentos de mensuração específicos da área da música. Verificou-se que a reduzida produção encontrada pode estar relacionada ao atraso em relação à Educação Musical, considerando barreiras: o atendimento educacional de crianças e jovens talentosos, a descontinuidade de programas para desenvolver o talento e a desvalorização da música e, elas, necessitam ser transpostas.
\end{abstract}

Palavras-chave: Educação Especial. Talento Musical. Avaliação. Revisão Sistemática

\begin{abstract}
Any person can manifest music talent in different moments of life and in all social and economic spheres. The identification and evaluation of music talent are considered complex tasks and the educational answer for the talented person requires investment, whether governmental and/or independent initiatives of public authority. From this understanding, it was asked which are the national and international scientific productions related to the identification and evaluation of music talent in the educational perspective. Therefore, this research aimed to search and analyze national and international scientific productions related to the identification and evaluation of music talent in the educational perspective. To achieve this goal, a systematic review was performed in three databases, two national and one international, without temporary cut. The data analysis was performed qualitatively. As a result, four empiric researches dedicated to the identification and evaluation of music talent through measuring instruments specific to music were found. It was noticed that the reduced production found may be related to the delay with regard to Music Education, considering some barriers: the educational service for talented children and young people, the discontinuity of programs to develop talent, the depreciation of music and, they need to be transposed.
\end{abstract}

Keywords: Special Education. Music Talent. Evaluation. Systematic Review

\section{INTRODUÇÃO}

Educação, Psicologia e Interfaces, Volume 4, Número 2, p.93-107, Abril/Junho, 2020.

ISSN: 2594-5343. DOI: 10.37444/issn-2594-5343.v4i2.190 
O talento musical apresenta-se em forma de camadas, da mais aparente e de fácil visualização, como a performance e o timbre vocal, até a mais profunda, a qual poderá se revelar somente quando o sujeito for exposto ao estudo da Música e, assim, ir se mostrando em meio ao processo de ensino e aprendizagem. A identificação do talento musical e a avaliação não são processos fáceis, requerem conhecimento e olhar atento dos educadores às manifestações dos estudantes.

Apresentar uma performance notável pode não ser sinônimo de talento, assim como não o são também gostar muito de música e se envolver com ela, bem como compor os versos de uma música ou apresentar alto escore em um teste de quociente de inteligência ${ }^{1}$ (QI). A pergunta que um especialista da área da Música se faz é: como e por que esse sujeito está compondo, tocando, construindo arranjos ou cantando? Como interage com a música? Que sentido tem a Música tem para ele?

Um profissional sem formação musical poderá facilmente ser induzido pela característica mais aparente de uma pessoa com indícios de talento musical, principalmente se ela for criança. A internet está repleta de exemplos dessa natureza, e alguns podem indicar o talento musical precoce em crianças apenas porque há uma realização considerada incrível naquele momento. Então, o que constitui e define o talento musical?

Para Teplov (1966, p. 25, tradução nossa ${ }^{2}$ ), “[...] o talento musical é a combinação qualitativamente original de aptidão que depende da possibilidade de prática bem sucedida em atividades musicais".

Kirnarskaya (2004), ao corroborar e se basear nas teorizações de Teplov (1966), argumentou que o talento musical reúne características como: habilidade para aquisição de conhecimento, motivação e criatividade. Para a autora, o talento musical depende de uma base preliminar composta pelo ouvido expressivo, senso rítmico, ouvido analítico, arquitetônico (senso estético) e habilidade produtivo-musical.

Gordon (2015, p. 17), nessa mesma perspectiva teórica dos autores anteriores, definiu o talento musical como "[...] a medida potencial de uma criança para aprender música $[\ldots] "$.

\footnotetext{
${ }^{1}$ Teste que mensura a inteligência geral.

2 “"...] talent musical la combinaison qualitativement originale d'aptitude dont dépend la possibilite de pratiquer avec succés l'activité musicale" (TEPLOV, 1996, p.25).
}

Educação, Psicologia e Interfaces, Volume 4, Número 2, p.93-107, Abril/Junho, 2020. 
Haroutounian (2002) sustenta que o sujeito talentoso em música manifesta o spark $^{3}$ que comanda o pensamento e o comportamento musical ou a musicalidade. Para Haroutounian (2002, p. 174, tradução nossa ${ }^{4}$ ), “[...] o spark do talento musical consiste na capacidade perceptiva sensorial para música, habilidade metaperceptiva interna para tomada de decisão e habilidade para se comunicar com as pessoas por meio da performance."

Winner (1996) teorizou sobre três características que podem se manifestar na criança talentosa, inclusive em música. São elas: precocidade, insistência em se desvencilharem sozinhas e sede enorme de conhecimento. Winner (1996, p. 16) assinala que as crianças que apresentam precocidade ${ }^{5}$ “[...]dão os primeiros passos na maestria de alguns domínios, numa idade inferior à média das outras crianças. Progridem, também, mais rapidamente em determinados domínios que as crianças normais, visto que essa aprendizagem lhes é mais fácil”. A respeito de se desvencilharem sozinhas, a citada autora (1996, p. 17) teoriza que as crianças com talento "[...] aprendem de um modo qualitativamente diferente. Caminham ao seu próprio ritmo: necessitam de ajuda ou apoio mínimo por parte dos adultos, para se tornarem competentes no seu domínio e na maior parte do tempo ensinam-se a si próprias". Por fim, a sede pelo conhecimento refere-se aos “[...] estados de concentração absoluta durante os quais perdem a noção do mundo exterior. A combinação favorável de um interesse obsessivo em determinado domínio e da capacidade de aprender facilmente".

Não são apenas as caracerísicas internas que operam na constituição do talento musical; é preciso considerar ainda questões de ordem cultural. A esse respeito, Lehmann, Sloboda e Woody (2007, p. 5, tradução nossa ${ }^{6}$ ) teorizam que “[...] cantar em uma banda de rock somente tornou-se possível no século XX no hemisfério ocidental, tocar cítara ainda acontece principalmente na Índia e os pigmeus da floresta tropical de Ituri não exigem um crítico de música". Portanto, a manifestação do talento se

\footnotetext{
${ }^{3}$ Faísca ou centelha, de acordo com o dicionário Webster's (HOUAISS, 2007).

4 "The spark of musical talent consist of the perceptive sensory capacities of music, the metaperceptive abilitiy to internally make musical decisions, and the ability to communicate personal musical ideas through performance" (HAROUTOUNIAN, 2002, p. 174).

5 Também Robinson (2015) compreende a precocidade como a combinação de fatores potenciais, funcionamento acelerado na internalização de elementos culturais e seus significados e aspectos motivacionais que mobilizam a criança de tenra idade.

6 "[...] singing in a rock band only became possible in the twentieth century in the western hemisphere, playing the sitar still mainly happens in India, and the pygmies of the Iture rain forest do not require a music critic." (LEHMANN; SLOBODA; WOODY, 2007, p. 5).
} 
condicionará aos aspectos, recursos e valorizações que determinada cultura considera significativamente importantes. Também estará condicionada à atividade que determinada cultura disponibiliza, como forma de trabalho, em certo momento histórico (RUBINSTEIN, 1978).

Em síntese, o talento musical se constitui de nuances, multifaces, aspectos de ordem cultural e características diversificadas, as quais são complexas em procedimentos de identificação e avaliação. Por essa razão, é de suma importância que educadores e profissionais especialistas em música tenham formação na área do talento musical, para que possam compreender as características apresentadas por pessoas talentosas.

Diante do exposto, emergiu o seguinte questionamento, que culminou nesta pesquisa: quais são as produções científicas, em âmbito nacional e internacional, relacionadas à identificação e avaliação do talento musical na perspectiva educacional?

Assim, o objetivo dessa pesquisa é buscar e analisar as produções científicas, em âmbito nacional e internacional, relacionadas à identificação e avaliação do talento musical na perspectiva educacional.

\section{MATERIAL E MÉTODO}

Para responder ao questionamento e objetivo propostos, foi realizada a pesquisa de revisão sistemática, a qual objetiva maximizar o potencial de uma busca, encontrando o maior número possível de resultados de forma organizada, constituindo um trabalho reflexivo, crítico e compreensivo dos materiais analisados (KOLLER; COUTO; HOHENDORFF, 2014).

Uma revisão sistemática agrupa, sintetiza e integra evidências científicas oriundas de resultados de pesquisas empíricas e metodologicamente controladas. "Esse tipo de investigação disponibiliza uma síntese ou resumo das evidências relacionadas à uma estratégia de intervenção específica (MEDRADOS; GOMES; SOBRINHO, 2014, p. 107).

A Figura 1 concatena as etapas percorridas na realização da presente revisão sistemática.

Educação, Psicologia e Interfaces, Volume 4, Número 2, p.93-107, Abril/Junho, 2020. 
Figura 1 - Etapas para a realização da busca

Bases:

Amplificar,

Biblioteca

Digital de Teses

e Dissertações

(BDTD) e Sage

Full-text

Collection
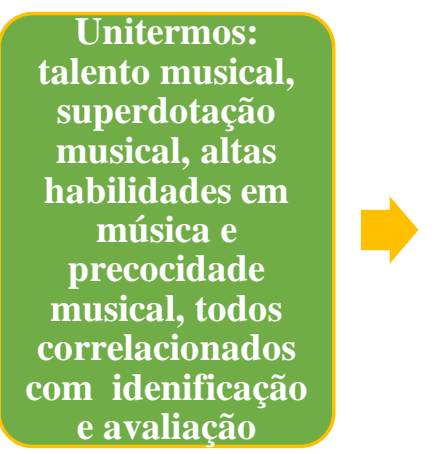
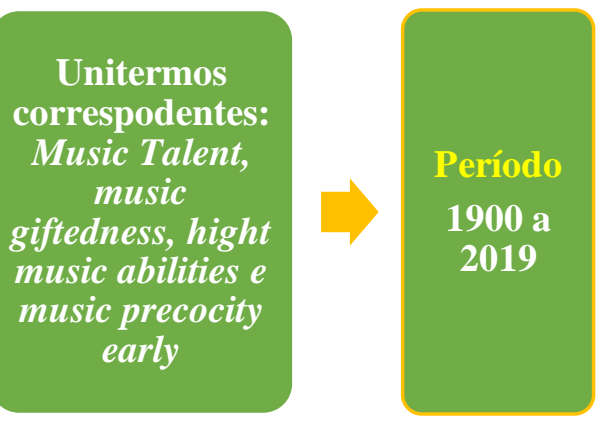

Fonte: elaborado pelas autoras

Para a realização da busca, foram consultadas as bases de dados: Amplificar ${ }^{7}$, Biblioteca Digital de Teses e Dissertações (BDTD) ${ }^{8}$ e Sage Full-Text Collection ${ }^{9}$. Os unitermos em língua portuguesa e seus correspondentes em inglês ${ }^{10}$ foram consultados no banco da Thesaurus Brasileiro da Educação ${ }^{11}$. Os unitermos foram respaldados no corpus teórico da área do talento e da música (GAGNÉ, 1985; HAROUOUNIAN, 2002; KIRNARSKAYA, 2004; LEHMANN; SLOBODA; WOODY, 2007; GAGNÉ; GUENTHER, 2012; ROBINSON, 2015; RENZULLI, 2018). Também, foram correlacionados com identificação e avaliação mediante uso do operador Booleno “AND”. O recorte temporal pesquisado foi de $1900^{12}$ a 2019.

Após a realização da busca nos bancos de dados, as pesquisas encontradas foram analisadas e discutidas qualitativamente e de modo descritivo (MEDRADOS; GOMES; SOBRINHO, 2014).

\section{RESULTADOS E DISCUSSÃO}

De acordo com a busca, o panorama de pesquisas encontradas, a partir da correlação com identificação e avaliação está demonstrado na Tabela 1:

\footnotetext{
${ }^{7}$ https://www.amplificar.mus.br/Busca\&b=talento\%20musical

${ }^{8} \mathrm{http}: / /$ bdtd.ibict.br/vufind/

${ }^{9} \mathrm{https}: / /$ journals.sagepub.com/

${ }^{10}$ Music talent, music giftedness, hight music abilities e music precocit early.

${ }^{11} \mathrm{http}$ ///inep.gov.br/thesaurus-brasileiro-da-educacao

12 Iniciar a busca no ano de 1900 ocorreu porque o banco de dados da Sage full Text Collection traz a digitalização de pesquisas datadas desse ano, as quais estavam disponíbilizadas nesse banco de dados.
}

Educação, Psicologia e Interfaces, Volume 4, Número 2, p.93-107, Abril/Junho, 2020.

ISSN: 2594-5343. DOI: $10.37444 /$ issn-2594-5343.v4i2.190 
Tabela 1 - Índice de pesquisas encontradas nas bases de dados nacionais e internacional Amplificar/BDTD/ Sage full Text Collection - 1900 a 2019.

\begin{tabular}{|c|c|c|c|}
\hline Unitermo (português/inglês) & Amplificar & BDTD & $\begin{array}{l}\text { Sage full- } \\
\text { text } \\
\text { collection }\end{array}$ \\
\hline Talento musical (music talent) & 4 & 25 & 270 \\
\hline Superdotação musical (music giftedness) & 1 & 1 & 24 \\
\hline Altas habilidades em música (hight music abilities) & 2 & 4 & 5 \\
\hline Precocidade musical (music precocity early) & 0 & 1 & 20 \\
\hline Total & 7 & 31 & 319 \\
\hline
\end{tabular}

O resultado preliminar geral permitiu concluir que as pesquisas de cunho empírico e que se dedicaram à descrição de procedimentos de identificação e avaliação a partir dos unitermos supracitados na Tabela 1 totalizaram um $n=38$ pesquisas considerando as duas bases de dados nacionais e 319 em âmbito internacional.

Mesmo utilizando unitermos relacionados ao talento musical, muitas pesquisas não eram exclusivamente dessa área. Um $n=347$ pesquisas versavam sobre o talento, superdotação e altas habilidades geral sem menção à área da Música. Nesse contexto, foi possível encontrar pesquisas que se propunham ao rastreamento do talento em geral. Essas pesquisas contemplavam, em pelo menos um de seus itens, informações para o rastreamento do talento musical. As pesquisas encontradas que tratavam do talento geral totalizaram um n=04, sendo Vieira (2005); Martins (2013); Mendonça (2015); Marques (2017).

Há pesquisas exclusivamente da área da Música que avaliaram o talento musical por meio de observação, precisamente, estudo de caso. Um dos sujeitos observados apresentava dupla excepcionalidade (deficiência e talento musical), e no outro caso, o foco foram questões de ordem socioeconômicas e de vunerabilidade social. Essas pesquisas totalizavam um $\mathrm{n}=02$ (GOMES, 2016; OGANDO, 2017).

A etapa final consistiu em selecionar pesquisas conduzidas por pesquisadores com formação em Música e com estudos que se dedicaram à identificação e avaliação do talento musical, exclusivamente, e em uma perspectiva de desenvolvimento educacional do sujeito identificado. O Quadro 1 traz uma síntese descritiva dessas produções consideradas relevantes para este estudo.

Quadro 1 - Pesquisas encontradas

Educação, Psicologia e Interfaces, Volume 4, Número 2, p.93-107, Abril/Junho, 2020. 


\begin{tabular}{|c|c|c|c|}
\hline Autor/ano/origem & Título & Objetivo & Resultados \\
\hline $\begin{array}{l}\text { Koga (2019), } \\
\text { Unesp, campus de } \\
\text { Marília/SP. } \\
\text { Programa de pós- } \\
\text { graduação em } \\
\text { Educação. }\end{array}$ & $\begin{array}{l}\text { Protocolo para } \\
\text { Screening de } \\
\text { Habilidades } \\
\text { Musicais (PSHM) }\end{array}$ & $\begin{array}{l}\text { Construir um } \\
\text { instrumento para } \\
\text { screening. }\end{array}$ & $\begin{array}{l}\text { O instrumento foi construído } \\
\text { e apresentou usabilidade, } \\
\text { porém a autora destacou a } \\
\text { necessidade de validação e } \\
\text { normatização. }\end{array}$ \\
\hline $\begin{array}{l}\text { Wolf e Kopiez } \\
\text { (2018), } \\
\text { Universidade de } \\
\text { Hamburgo, } \\
\text { Alemanha. } \\
\text { Programa de pós- } \\
\text { graduação em } \\
\text { Música }\end{array}$ & $\begin{array}{l}\text { Development and } \\
\text { Validation of the } \\
\text { Musical Ear } \\
\text { Training } \\
\text { Assessment } \\
\text { (META) }\end{array}$ & $\begin{array}{l}\text { Criar um } \\
\text { instrumento de } \\
\text { mensuração da } \\
\text { acuidade } \\
\text { auditiva analítica } \\
\text { (percepção } \\
\text { musical). }\end{array}$ & $\begin{array}{l}\text { Os autores concluíram que o } \\
\text { instrumento permite } \\
\text { averiguar empiricamente o } \\
\text { desenvolvimento auditivo } \\
\text { para habilidades musicais. }\end{array}$ \\
\hline $\begin{array}{l}\text { Koga (2015), } \\
\text { Unesp, campus } \\
\text { Marília/SP. } \\
\text { Programa de pós- } \\
\text { graduação em } \\
\text { Educação. }\end{array}$ & $\begin{array}{l}\text { Avaliação } \\
\text { comparativa em } \\
\text { educação e música } \\
\text { entre crianças } \\
\text { precoces com } \\
\text { comportamento de } \\
\text { superdotação e } \\
\text { crianças com } \\
\text { desenvolvimento } \\
\text { típico }\end{array}$ & $\begin{array}{l}\text { Identificar o } \\
\text { nível de aptidão } \\
\text { musical e as } \\
\text { diferenças na } \\
\text { superdotação } \\
\text { para música em } \\
\text { um universo de } \\
51 \text { participantes. }\end{array}$ & $\begin{array}{l}\text { Foram encontrados três } \\
\text { estudantes que demonstraram } \\
\text { precocidade e } \\
\text { comportamento de } \\
\text { superdotação musical ao } \\
\text { atingirem os melhores } \\
\text { resultados. A autora sugeriu } \\
\text { o enriquecimento musical } \\
\text { para os sujeios identificados. }\end{array}$ \\
\hline $\begin{array}{l}\text { Rodrigues (2004), } \\
\text { Universidade Nova } \\
\text { de Lisboa, } \\
\text { Portugal. }\end{array}$ & $\begin{array}{l}\text { Esudo de validade } \\
\text { do teste } \\
\text { Intermediate of } \\
\text { Music Audiaion, de } \\
\text { Edwin Gordon, } \\
\text { para uma situação } \\
\text { de desempenho } \\
\text { musical de crianças } \\
\text { do } 1^{\circ} \text { ano de } \\
\text { escolaridade. }\end{array}$ & $\begin{array}{l}\text { Adaptar e validar } \\
\text { o teste } \\
\text { Intermediate of } \\
\text { Music Audiaion } \\
\text { para a realidade } \\
\text { portuguesa. }\end{array}$ & $\begin{array}{l}\text { Os resultados predizem } \\
\text { parcialmente o desempenho } \\
\text { vocal das crianças. }\end{array}$ \\
\hline
\end{tabular}

Fonte: elaborado pelas autoras

Koga (2019) se dedicou à construção de um protocolo screening para aplicação em massa, com usabilidade para professores e especialistas interessados em identificar casos iniciais de talento musical. O protocolo conta com 127 itens divididos em oito dimensões (timbre, altura, melodia, intensidade, harmonia, agógica, duração e padrãorítmico) na versão de construção. Ele foi aplicado em escolas públicas e privadas, em uma cidade do Centro-Oeste do Estado de São Paulo, totalizando um n=653 participantes, de 6 a 11 anos. De acordo com os resultados, Koga (2019) concluiu que o protocolo apresentou usabilidade e conseguiu rastrear casos iniciais de talento musical.

Educação, Psicologia e Interfaces, Volume 4, Número 2, p.93-107, Abril/Junho, 2020. 
Porém, a autora enfatizou a necessidade de validação e normatização do protocolo para que sua capacidade de mensuração seja assegurada, e que se possa garantir confiabilidade. A autora enfatiza que o protocolo se destina para a área da Educação e que, de modo algum, foi desenvolvido para ranquear os sujeitos que passarem pelo processo de screening. A autora enfatiza que o protocolo PSHM foi criado para designar sujeitos com talento musical com a finalidade de ajudá-los e conduzi-los em seu processo educativo.

Wolf e Kopiez (2018) também criaram um instrumento de testagem da acuidade auditiva. Na testagem inicial, o Musical Ear Training Assessment (META), após a análise dos testes de Resposta ao Item, alcançou um montante de 53 itens mensurando adequadamente. No entanto, os autores notaram a necessidade de elaboração de duas versões (META-10 itens; META-25 itens). Os autores concluiram, com base nas análises psicométricas e correlações, que o instrumento apresenta validade na realidade para a qual foi criado. O META foi aplicado em 393 participantes na validação final, no entanto, anterior a essas testagens, outros participantes haviam passado pelo projeto piloto e etapas de aplicação para o refinamento dos itens. Ressalta-se que o instrumento não está validado para a realidade brasileira e condiciona-se ao ensino e aprendizagem musical. Os autores não criaram esse instrumento para pessoas sem experiência musical.

Koga (2015) objetivou, em sua pesquisa, identificar o nível de aptidão musical e as diferenças no talento para música de 51 participantes ${ }^{13}$, avaliados a partir dos instrumentos psicométricos para rastreamento denominados Primary Measures of Music Audiation e Intermediate Measures of Music Audiation, de autoria de Gordon (2000). Para a avaliação mediante observação, Koga (2015) utilizou a Ficha orientadora para observação da conduta musical, de Gainza (1988). Mediante análise de correlação, a autora concluiu que três participantes tinham talento musical devido à alta pontuação nos intrumentos padronizados e à manifestação dos indicadores e características do talento musical observados em atividades, a partir dos requisitos da ficha de observação. A autora também concluiu que, por mais que os instrumentos fossem adaptados para a

\footnotetext{
${ }^{13}$ Oriundos do Programa de Atenção ao aluno Precoce com Comportamento de Superdotação (PAPCS), pareados em idade e ano escolar com estudantes da educação básica de uma cidade do Centro-Oeste paulista. O PAPCS foi um projeto de extensão da Faculdade de Filosofia e Ciências, UNESP, campus de Marília/SP e coordenado pelo Dr. Miguel C. M. Chacon.
}

Educação, Psicologia e Interfaces, Volume 4, Número 2, p.93-107, Abril/Junho, 2020. 
realidade brasileira, alguns aspectos como sons e ritmos não se alinhavam às diferenças e características peculiares presentes na música brasileira.

Rodrigues (2004) objetivou adaptar o instrumento psicométrico Intermediate Measures of Music Audiation para a realidade portuguesa. Participaram da pesquisa 37 crianças do $1^{\mathrm{o}}$ ano do $1^{\mathrm{o}}$ ciclo de escolaridade. A autora concluiu que o instrumento prediz parcialmente o desempenho vocal das crianças. Também sinalizou a necessidade de estudos futuros para investigar se esse instrumento antecipa situação de desempenho musical.

As escalas de mensuração da acuidade auditiva não são os únicos recursos para a identificação e avaliação do talento musical. No entanto, quando se trata de rastreios iniciais e em massa ou grande escala, medir a acuidade auditiva torna-se prático porque há recursos e instrumentos disponíveis e validados em alguns casos, como se viu no Quadro 1, e são procedimentos de fácil aplicação em grupo e tabulação rápida em um momento histórico no qual professores não dispõem de tempo para dar uma resposta educativa rápida.

Gagné e Guenther (2012) evidenciam que se pode encontrar 10\% de sujeitos talentosos em uma área de conhecimento rastreada. Quando não há rastreamento, muitas vezes talentosos musicais ficam invisíveis e em sofrimento psíquico por falta de apoio educacional e acolhimento por parte das escolas.

Rubinstein (1978) já argumentava a importância do trabalho como uma atividade humana para a constituição do sujeito e de sua identidade. Identificar uma pessoa talentosa muitas vezes implica fornecer orientações que permitem canalizar seu potencial na direção de suas habilidades. A designação não está apenas nas mãos daqueles que fazem esse tipo de procedimento, mas também nas do sujeito que, nesse processo, começa a se conhecer, se compreender e aprende a se tornar resiliente diante do meio social. Diante disso, o sujeito talentoso se emancipa porque compreende a natureza de suas habilidades e comportamentos e, na troca com seus mentores, aprende a dar vazão para todo o seu potencial, de modo calmo e planejado. Por meio do trabalho musical, ele ou ela encontra seu lugar no mundo.

Gordon (2015) também discutiu a importância dos procedimentos de identificação e avaliação musical permanente, possibilitando a compreensão da percepção musical e como ela se desenvolve entre os indivíduos a partir da Educação 
Musical. A partir disso, professores e familiares, de modo colaborativo, poderão orienta-los melhor. Para o referido autor, designar tem a função de estabelecer um ponto inicial, pois esses parâmetros referentes às faixas de aptidão musical contribuem para a prática dos professores em sala de aula.

Haroutounian (2002) e Kirnarskaya (2004) corroboram essa perspectiva quando argumentam a importância da identificação, avaliação e, sobretudo, da resposta educativa. Para elas, designar esses sujeitos é dar a eles oportunidade para que façam arte, para que se encontrem neste mundo e para que tenham a possibilidade de deixarem suas marcas na história. Kirnarskaya (2004) assinala que todas as pessoas podem se tornar homos musicus ${ }^{14}$ e Harouounian (2002) destaca que a descoberta do talento está vinculada à descoberta da centelha (spark). Para que isso ocorra, a criança talentosa precisa vivenciar e experimentar a música o mais cedo possível.

Sobre a musicalidade precoce, Robinson (1987) e Winner (1996) postulam que ela pode se revelar no indivíduo quando ele ainda é um bebê. Winner (1996) discute que a área da música é uma das que mais cedo revela casos de talento musical. Ambas as autoras assinalam que essas crianças se desenvolvem antes de seus pares em sua área de interesse e aprendem com autonomia e de modo acelerado.

Em síntese, Teplov (1966) teoriza que pessoas talentosas tendem a apresentar aptidão auditiva elementar, além de outros aspectos como o senso estético, criatividade e motivação. No entanto, para que suas aptidões auditivas se tornem superiores e para que tenham a consciência musical desenvolvida, emancipação para decidir o que criar e produzir na área da Música, essas pessoas necessitarão de oportunidade para se desenvolver musicalmente.

Assim, será preciso que a legislação seja cumprida. Para isso, as pessoas com talento e suas famílias precisam conhecer a lei e lutar para que ela de fato seja colocada em prática nos ambientes escolares. Tanto o talento quanto a Música, no Brasil, estão à margem em termos de valorização, por isso, o incentivo à busca legal pelos direitos da pessoa com talento. A esse respeito, Lehmann, Sloboda e Woody (2007) já discutiram a importância da identidade musical e cultural dos povos e o quanto a valorização é

\footnotetext{
${ }^{14}$ Se constiui a partir da percepção aural associada ao movimento e gestos. Trata-se do mundo visual e das sensações onde o homem iniciou seu processo de significação e comunicação mediante o balbucio e gestos. Assim, surgiu o ouvido expressivo "expressive ear" dando condições ao homem de exploração do campo aural musical. Quando surge o ouvido expressivo surge o homos musicus (KIRNARSKAYA, 2004).
}

Educação, Psicologia e Interfaces, Volume 4, Número 2, p.93-107, Abril/Junho, 2020. 
importante para que uma área ou muitas outras sigam existindo ao longo da história. Quantas profissões não existem mais e quantas vão deixar de existir por conta da valorização atribuída pela sociedade capitalista? A escola, nesse sentido, não está isenta nessa valorização.

Refletindo sobre essa questão, a tecnologia poderia ser uma ferramenta importante, por exemplo, se utilizada como conexão com especialistas e possíveis mentores durante os procedimentos de identificação e avaliação e em relação à resposta educativa. Também, poderia contribuir com trocas de experiências e viabilizando que especialistas, professores e profissionais interessados pelo talento pudessem dialogar, inclusive, em diferentes partes do mundo, como uma rede colaborativa.

\section{CONSIDERAÇÕES FINAIS}

O atraso do Brasil em relação à Educação Musical, ao atendimento educacional de crianças e jovens talentosos, à valorização da música no âmbito da Educação, e a continuidade de programas para o talento são barreiras consideráveis e que necessitam ser transpostas pelos profissionais da área da música, pelos profissionais da educação geral e especialistas que se dedicam ao estudo do talento. Os estudantes talentosos em música e artes, bem como muitos outros estudantes talentosos em outras áreas, estão invisíveis nos ambientes escolares e na sociedade.

Os profissionais da Música também são passíveis do desconhecimento e formação adequada a respeito das nuances que compõem o talento musical. Assim, o desenvolvimento de um sujeito identificado como talentoso musicalmente certamente será prejudicado se seu mentor não tiver formação adequada.

A identificação e a avaliação do talento musical são importantes devido à possibilidade de proporcionar à criança ou ao jovem que eles se expressem e que sejam notados e compreendidos por suas famílias, escolas e sociedade. Isso significa que a identificação e a avaliação contribuem para a constituição da identidade do sujeito, sua emancipação, e proporcionam melhor qualidade de vida, além de fornecer ao educador informações que se tornam ponto de partida para o planejamento pedagógico e musical.

Para que a criança ou o jovem talentoso em Música possam ser encontrados em meio à invisibilidade, a legislação referente à implementação da Educação Musical e a que garante a identificação e atendimento especializado do talento precisam ser 
colocadas em prática. Enquanto isso não ocorrer, talentos estarão esquecidos e se perdendo. Se a Educação Musical e a Arte estivessem efetivamente na escola, de fato, todos os estudantes e os talentos artísticos estariam sendo contemplados de algum modo.

Também diferentes instrumentos de mensuração e de rastreamento do talento são imprescindíveis para ampliar o crivo e atender às nuances do fenômeno. Uma única modalidade para identificar e avaliar pode deixar muitos talentos musicais fora de serviços que possam prover a resposta educativa necessária. Não há uma fórmula pronta e uma única pessoa que possam ser capazes de realizar a identificação, a avaliação e o enriquecimento de uma criança ou jovem com talento musical. Os resultados dessa pesquisa mostraram quão escassos são os estudos dedicados à avaliação do talento e os instrumentos são praticamente similares.

No momento histórico atual, a designação do talento musical torna-se fundamental, porém em um futuro pode ser que a sociedade tenha se desenvolvido de tal maneira que se preocupar com o talento, inclusive musical, seja uma meta para A Educação e para a manutenção da democracia, da liberdade e da emancipação dos povos com a finalidade de deixar contribuições para as gerações precedentes.

\section{REFERÊNCIAS BIBLIOGRÁFICAS}

GAGNÉ, F.; GUENTHER, Z. Desenvolvendo Talentos: modelo diferenciado de dotação e talento - DMGT 2.0. In: MOREIRA, L. C.; STOLTZ, T. Altas

habilidades/superdotação, talento, dotação e educação. Curitiba: Juruá, 2012, p. 19 44.

GOMES, J. M. O Rap de Mc Criolo entre talentos e tecnologia. 2016. 211f. (Tese de doutorado) - Programa de Pós-Graduação em Música, Universidade Federal do Estado do Rio de Janeiro, Rio de Janeiro, 2016. Disponível em: http://www.repositoriobc.unirio.br:8080/xmlui/handle/unirio/11024. Acesso em: 09 set. 2019.

GORDON, E. E. Teoria de aprendizagem musical para recém-nascidos e crianças em idade pré-escolar. Tradução de Paula Maria Rodrigues; Victor Gaspar. $4^{a}$ ed. Lisboa: Fundação Calouste Gulbenkian, 2015.

HAROUTOUNIAN, J. Kindling the spark: recognizing and developing musical talent. New York: Oxford, 2002.

KIRNARSKAYA, D. The natural musician: on abilities, giftedness and talent. Tradução de Mark H. Teeter. New York, 2004.

Educação, Psicologia e Interfaces, Volume 4, Número 2, p.93-107, Abril/Junho, 2020. 
KOLLER, S. H.; COUTO, M. C. P. de P.; HOHENDORFF, J. V. Manual de produção científica. Porto Alegre: Penso, 2014.

KOGA, F. O. Avaliação comparativa em educação e música entre crianças precoces com comportamento de superdotação e crianças com desenvolvimento típico. 2015. 180f. Dissertação (Mestrado em Educação) - Universidade Estadual Paulista, Faculdade de Filosofia e Ciências, Marília. 2015. Disponível em:

https://repositorio.unesp.br/handle/11449/123126. Acesso em: 09 set. 2016.

KOGA, F. O. Protocolo para Screening de Habilidades Musicais. 2019. 250f. Tese. (Doutorado em Educação) Programa de Pós-graduação em Educação da Universidade Estadual Paulista, Faculdade de Filosofia e Ciências, Marília. 2019. Disponível em: https://repositorio.unesp.br/handle/11449/182213. Acesso em: 09 set. 2019.

LEHMANN, A. C.; SLOBODA, J. A.; WOODY, R. H. Psychology for musicions: understanding and acquiring the skills. Nova York: Oxford, 2007.

MARTINS, B. A. Alunos precoces com indicadores de altas habilidades/superdotação no ensino fundamental I: identificação e situações (des)favorecedoras em sala de aula. 2013. 238 f. (Dissertação de Mestrado) - Programa de Pós-Graduação em Educação, Universidade Estadual Paulista, Faculdade de Filosofia e Ciências, Marília, 2013. Disponível em: https://repositorio.unesp.br/handle/11449/91210. Acesso em 09 set. 2019.

MARQUES, D. M. C. Aluno com altas habilidades/superdotação: um estudo longitudinal a partir da teoria das inteligências múltiplas. 2017. 201f. (Tese de doutorado) - Programa de Pós-Graduação em Educação Especial, Universidade Federal de São Carlos, São Carlos, 2017. Disponível em:

https://repositorio.ufscar.br/bitstream/handle/ufscar/10162/MARQUES_Danitiele_2018. pdf? sequence $=6 \&$ isAllowed $=\mathrm{y}$. Acesso em: 09 set. 2019.

MENDONÇA, L. D. Identificação de alunos com altas habilidades ou superdotação a partir de uma avaliação multimodal. 2015. 129 f. (dissertação de mestrado) Programa de Pós-graduação em Psicologia do desenvolvimento e aprendizagem, Faculdade de Ciências da Universidade Estadual Paulista, Bauru, 2015. Disponível em: https://repositorio.unesp.br/bitstream/handle/11449/124021/000828019.pdf?sequence $=1$ Acesso em: 09 set. 2019.

MEDRADO, C.; GOMES, V. M.; NUNES SOBRINHO, F.; P. Atributos teóricometodológicos da Revisão Sistemática das Pesquisas Empíricas em Educação Especial: Evidências Científicas na Tomada de Decisão sobre as Melhores Práticas Inclusivas. São Carlos: Marquezine \& Manzini: ABPEE, 2014.

OGANDO, M. G. C. Particularidades do desenvolvimento musical de um aluno observado com múltiplos sinais de talento entre estudantes cegos. 2017. 265f. (Tese de doutorado) - Programa de Pós-graduação em música, Universidade Federal do Estado do Rio de Janeiro, Rio de Janeiro, 2017. Disponível em: http://www.repositoriobc.unirio.br:8080/xmlui/handle/unirio/11580. Acesso em: 10 set. 2019. 
ROBINSON, N. The early development of precocity. Gifted Child Quartely. New York, v. 3, n. 4, 1987. Disponível em:

https://journals.sagepub.com/doi/10.1177/001698628703100406. Acesso em: 29 set. 2019.

RODRIGUES, H. Estudo de validade do teste Intermediate of Music Audiation de Edwin Gordon para uma situação de desempenho musical de crianças do $1^{\circ}$ ano de escolaridade. Revista da Escola Superior de Educação de Castelo Branco. Portugal, n.10, p. 11-23, 2004. Disponível em: https://repositorio.ipcb.pt/handle/10400.11/1755. Acesso em: 10 set. 2019.

RUBINSTEIN, J. L. Principios de Psicologia general. Trad. Sarolta Trowsky. México: Grijalbo, 1967.

TEPLOV, B. M. Psichologie des aptitudes musicales. Paris: Universitaries de France, 1966.

VIEIRA, N. J. W. Viagem a "Mojave-ÓKI!": Uma trajetória na identificação das Altas habilidades/superdotação em crianças de quatro a seis anos. 2005. 228f. (Tese de doutorado) - Programa de Pós-Graduação em Educação, Universidade Federal do Rio Grande do Sul, Faculdade de Educação, Rio Grande do Sul, 2005. Disponível em: https://www.lume.ufrgs.br/bitstream/handle/10183/6834/000491113.pdf?sequence=1. Acesso em: 10 set. 2019.

WINNER, E. Crianças sobredotadas: mitos e realidades. Tradução de Aurora Narciso ROSA. Lisboa: Instituto Piaget, 1996.

WOLF, A.; KOPIEZ, R. Development and validation of the musical ear training assessment (META). Journal of Research in Music Education. Hamburg/Alemanha, n. 66, p. 53 - 70, 2018. Disponível em:

https://journals.sagepub.com/doi/10.1177/0022429418754845. Acesso em: 11 set. 2019

\section{Credenciais das autoras}

KONGA, Fabiana Oliveira. Graduação em instrumento piano e em Educação Musical pela Universidade do Sagrado Coração, Bauru/SP. Pós-Graduada em Psicopedagogia clínica pela Faculdade Paulista, é Mestre e doutora em Educação pela Universidade Estadual Paulista - Faculdade de Filosofia e Ciências, campus de Marília. Durante o mestrado foi bolsista $\mathrm{CNPq}$ e, durante o doutorado, foi bolsista da Fundação de Amparo à Pesquisa do Estado de São Paulo (FAPESP). É autora do livro "Precocidade e Superdotação Musical" e autora, com o apoio da FAPESP, do "Protocolo para Screening de Habilidades Musicais". Participou do projeto de extensão Programa de Atenção ao aluno Precoce com comportamento de Superdotado (PAPCS) e foi membro do Grupo de Pesquisa Educação e Saúde de Grupos Especiais em parceria com a Faculdade de Medicina de Marília (FAMEMA). Em 2017 participou do curso de formação com Joseph S. Renzulli na Universidade de Connecticut. Foi membro do

Educação, Psicologia e Interfaces, Volume 4, Número 2, p.93-107, Abril/Junho, 2020. 
grupo de pesquisa Diferença, Desvio e Estigma sob a coordenação do Professor Dr. Sadao Omote da Faculdade de Filosofia e Ciências, UNESP e, atualmente, é membro do Grupo de Pesquisa para o Desenvolvimento do Potencial Humano (GRUPOH).

RANGNI, Rosemeire de Araújo. Graduação em Pedagogia pela Universidade de Guarulhos (2002), graduação em Direito - Faculdades Integradas de Guarulhos (1982), mestrado em Educação - Universidade Cidade de São Paulo (2005) e doutorado em Educação Especial Universidade Federal de São Carlos (2012). Atualmente é professora da Universidade Federal de São Carlos. Tem experiência na área de Educação, com ênfase em Educação Especial, atuando principalmente nos seguintes temas: altas habilidades/superdotação, atendimento educacional especializado, gestão educacional e surdocegueira. É lider do Grupo de Pesquisa para o Desenvolvimento do Potencial Humano (GRUPOH) (UFSCar) e vice lider do Grupo de Pesquisa Excelência, Sustentabilidade e Inovação Social: Engenharia das Organizações Criativas e Soluções Tecnológicas Educacionais (UNIRIO). Coordenadora do Laboratório de Pesquisa de Altas Habilidades (LAPAH). Membro da Red Internacional de Investigación, Intervención y Evaluaciónen Altas Capacidades Intelectuales (REINEVA). Membro da Comissão Técnica do Conselho Brasileiro para Superdotação (ConBraSD).

Endereço para correspondência: Fabiana Oliveira Koga. Rua José Matheus Carlos, n. 269, Bairro: Prolongamento Palmital, CEP: 17511393, Cidade/estado: Marília/SP.

E-mail: fabianapsicopedagogiamusical@gmail.com.

Endereço para correspondência: Programa de Pós-Graduação em Educação Especial (PPGEEs). Centro de Educação e Ciências Humanas. Rodovia Washington Luis, Km 235, São Carlos/SP - BR - CEP: 13565-905. E-mail: rose.rangni@uol.com.br

\section{Como citar este artigo (Formato ABNT):}

KOGA, Fabiana Oliveira; RANGNI, Rosemeire de Araújo. Talento musical: revisão sistemática de produções em banco de dados. Educação, Psicologia e Interfaces, v. 4, n.2, p. 93-107, 2020. Doi: 10.37444/issn-2594-5343.v4i2.190

Recebido: 20/10/2019.

Aceito: 20/01/2020.

Educação, Psicologia e Interfaces, Volume 4, Número 2, p.93-107, Abril/Junho, 2020.

ISSN: 2594-5343. DOI: 10.37444/issn-2594-5343.v4i2.190 